\title{
ISCHIO-FEMORAL ARTHRODESIS
}

\section{H. A. Brittain, Norwich, England *}

Accurate diagnosis has disabused our minds of the notion that it is possible to preserve mobility of the hip joint after tuberculous infection. At present, arthrodesis is the accepted form of treatment, and for joints which have been disorganised by disease it will probably remain so, though future developments in antibiotics may change this conception.

Ischio-femoral arthrodesis offers certain advantages over the various types of ilio-femoral arthrodesis. It is not suggested that this is the only operation by which to fuse a diseased hip, but it is suggested that it may be performed with success more often than any other. Ischio-femoral fusion may not, however, be feasible in every patient with a tuberculous hip. The ischium is a more rare site for extension of disease than the ilium, but it is occasionally involved, and a graft which is placed in a tuberculous area will probably fail. The graft may be able to traverse the diseased area and find a firm seat in healthy bone at each end, thus immobilising the joint for sufficient time to allow the disease to heal, but it will probably be eaten into and sustain fracture. Nevertheless, a graft in compression has

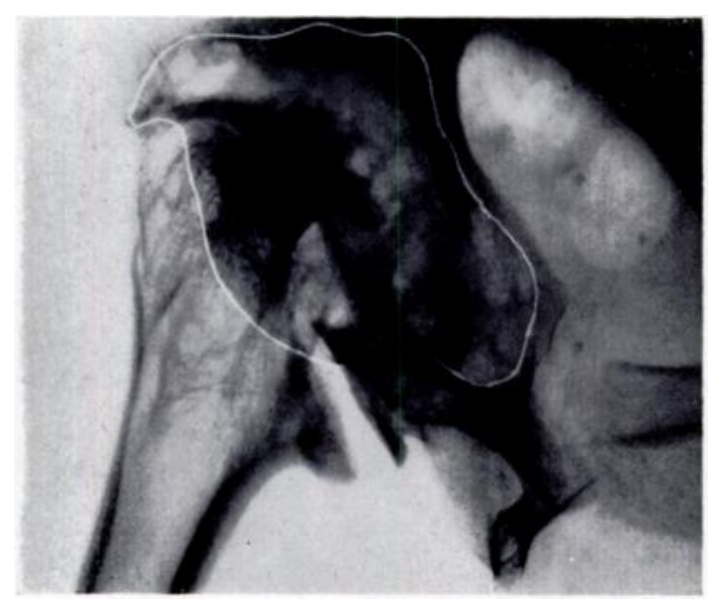

FIG. 1

The area of old disease is outlined with a pencil and an endeavour is made to keep outside this area during the operation. more chance of uniting after fracture than a graft in tension, which has little or none.

It is essential, therefore, to visualise the disease and the patient as a whole, to consider the form of arthrodesis which is most likely to succeed, and to decide at what stage, and at what best time, to perform the arthrodesis. It is now my custom to outline with a pencil the area of disease shown in the X-ray, and to try to keep outside this area in the course of the operation. If an ilio-femoral arthrodesis appears to offer a better chance of healing, then I carry this out. It is to be recognised, however, that the osteotomy performed in an ischio-femoral operation confers a unique advantage on the tuberculous hip, unlike other joints, in that the disease can be short-circuited and changed from the serious problem of joint disease to the less serious one of bone disease.

Stages of the operation-1) The patient having been placed on an orthopaedic table with his feet attached to the foot pieces and with the limbs in slight traction, two Michel clips are placed over the front of the hip joint. A calibrated guide is inserted on the antero-inferior aspect of the shaft and neck of the femur. An X-ray photograph is taken. An orthopaedic table is used so that there will be no pressure from behind which might press the sciatic nerve forwards against the neck of the femur.

2) While the photograph is being developed, a tibial bone graft is cut. I prefer to take it from the affected limb in order that the patient may have at least one sound limb upon which to walk when he is convalescent. It is essential to cut a wide tibial graft. The whole basis of the operation of ischio-femoral arthrodesis is the use of a wide tibial graft, which is more

* Paper read at the combined meeting of the American, British, and Canadian Orthopaedic .Associations, Quebec, June 1948. 


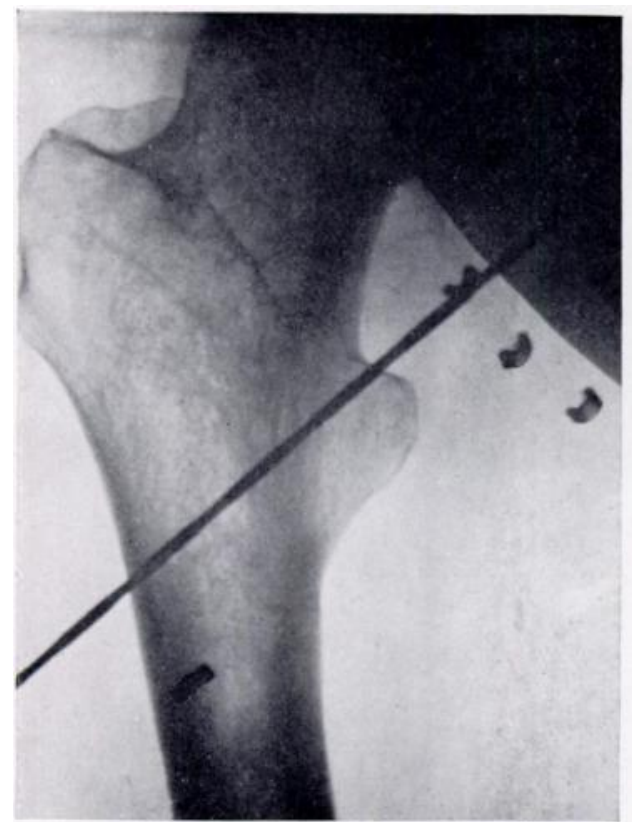

FIG. 2

Theatre radiograph of clips fixcd on the skin, and of the calibrated guide in the bone.

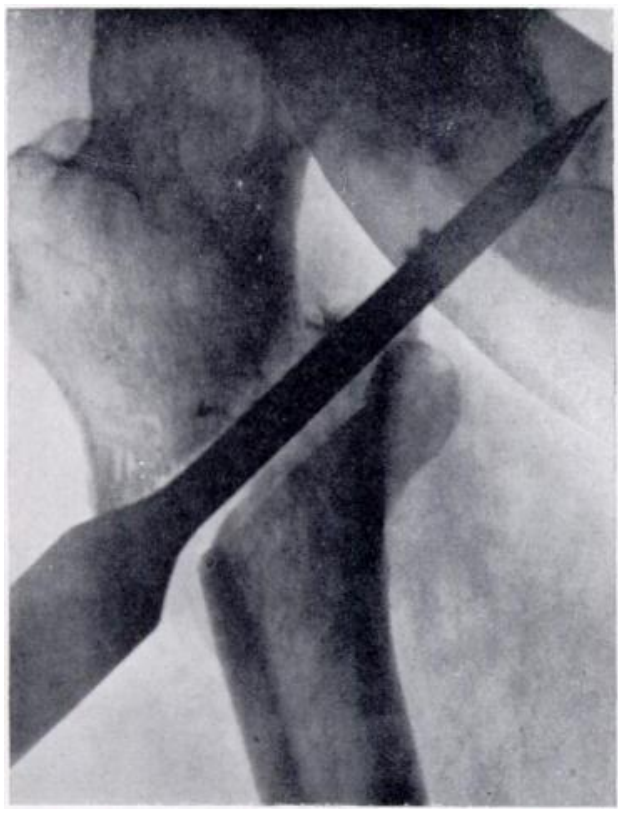

FIG. 4

Theatre radiograph of the chisels in situ. There is cvidence of ischial penctration at the point of the chisels.

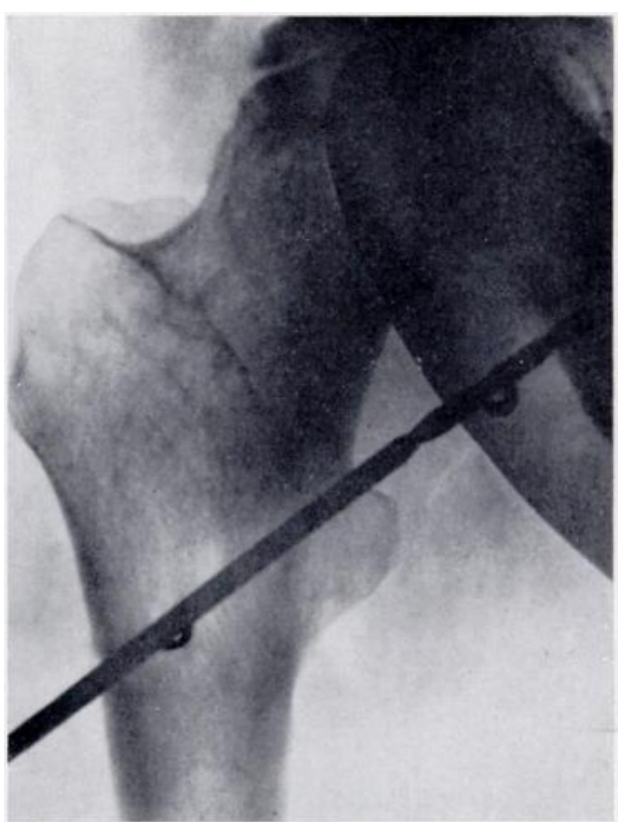

FIG. 3

Theatre radiograph of the drill in position, through the femur into the ischium.

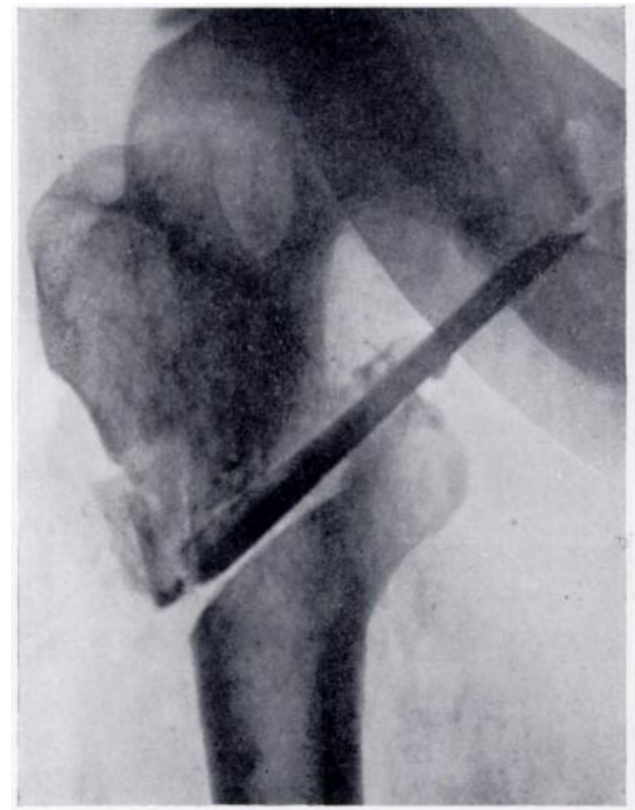

FIG. 5

Theatre radiograph of the graft in sitı. The outer surface of the trochanter has been fragmented; the shaft is being displaced inwards.

vol. $30 \mathrm{~B}$, No. 4 , November 1948

E 


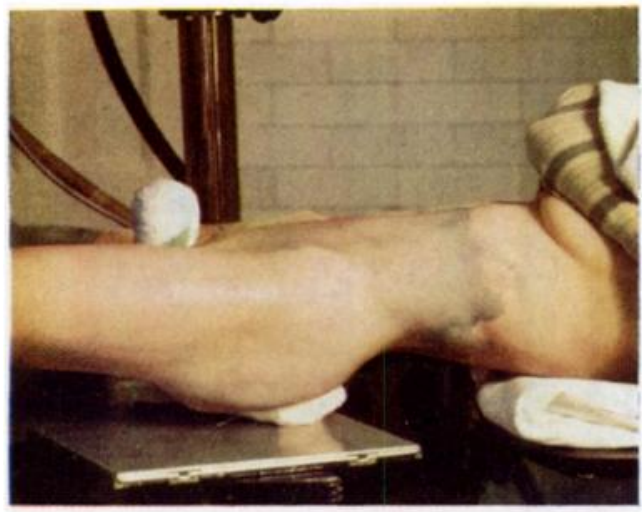

FIG. 6

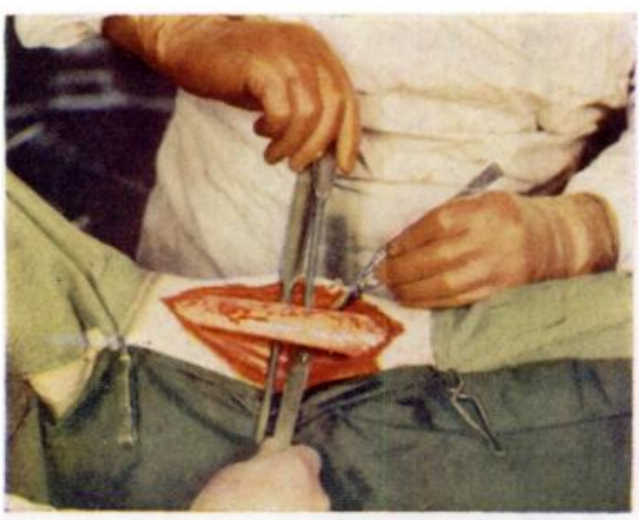

Fig. 8

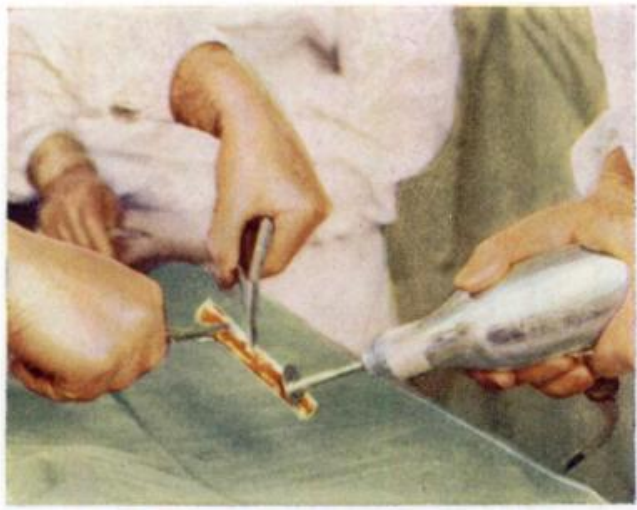

FIG. 10

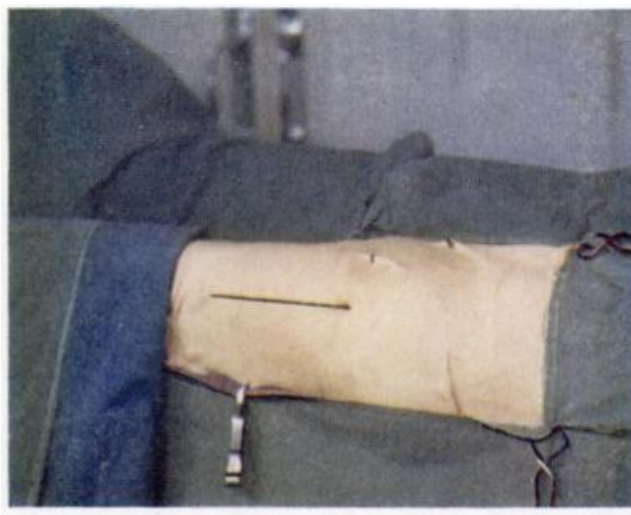

FIG. 7

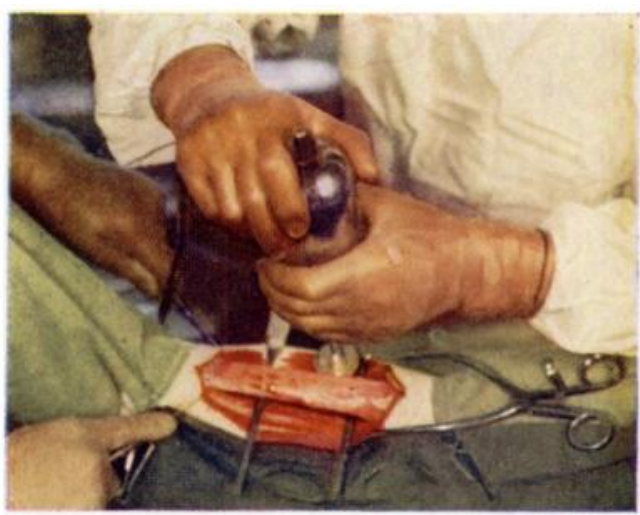

FIG. 9

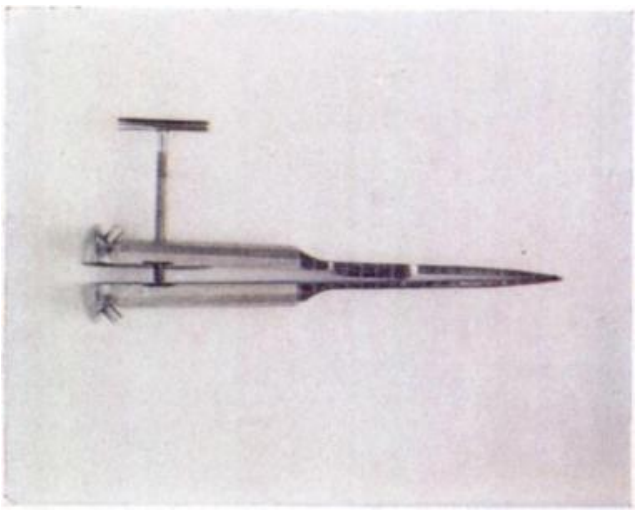

FIG. 11

Fig. 6 shows the patient on an orthopaedic table with cassette in position; note that there is no pressure from behind, displacing the sciatic nerve forwards. In Fig. 7, two Michel clips have been fixed, one over the greater trochanter and one on the middle point of the line from anterior superior iliac spine to the symphysis pubis; a calibrated guide has been passed in front and below the femoral neck. Figs. 8 and 9 show the graft being cut from the whole width of the tibia including the postero-medial and postero-lateral borders. One end of the graft is then cut to the shape of a chisel (Fig. 10). Fig. 11 shows the twin chisels, one with a ridge and shoulders to receive the other; they can be separated by the screw so that the cleft in the ischium is widened; each has a round projection so that it can be tapped out with a punch. 


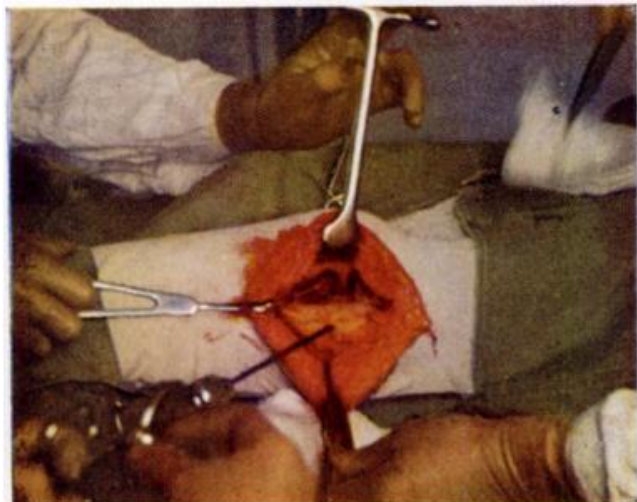

FIG. 12

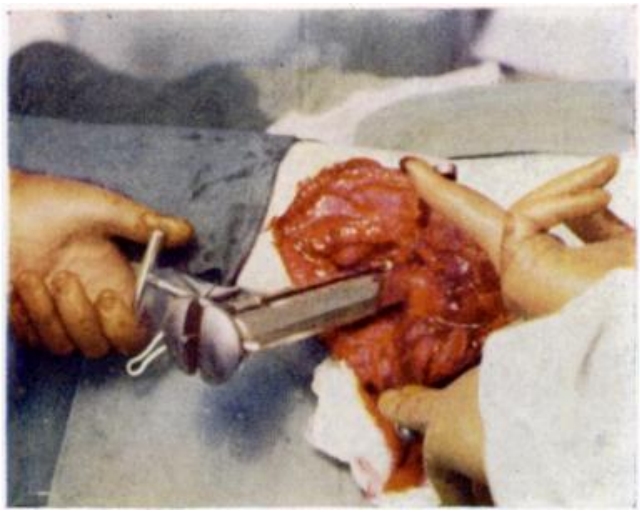

FIG. 14

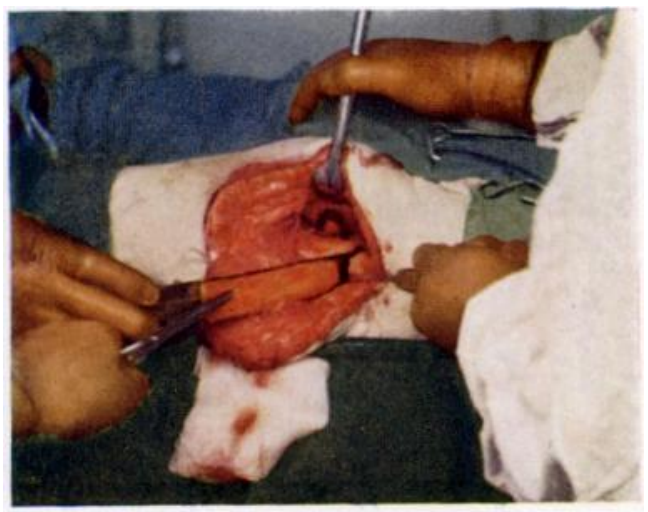

FIG. 16

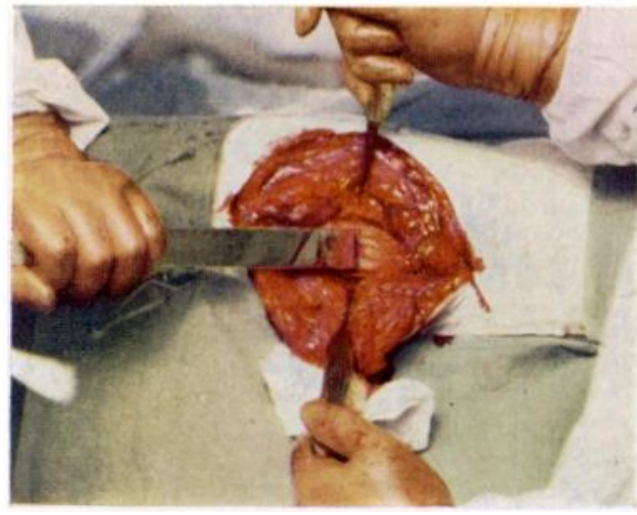

FIG. 13

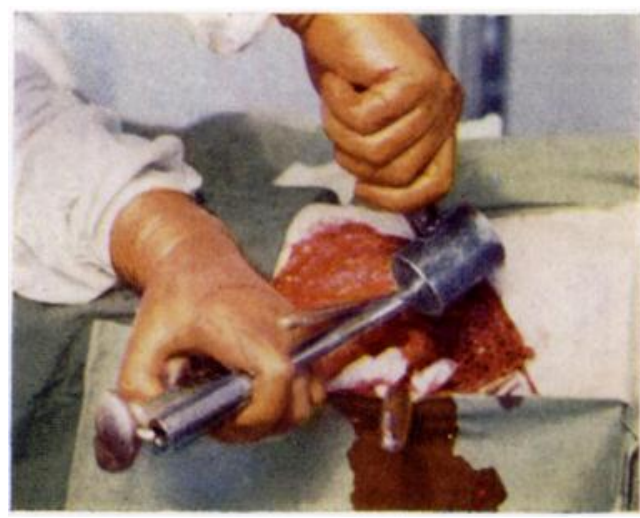

FIG. 15

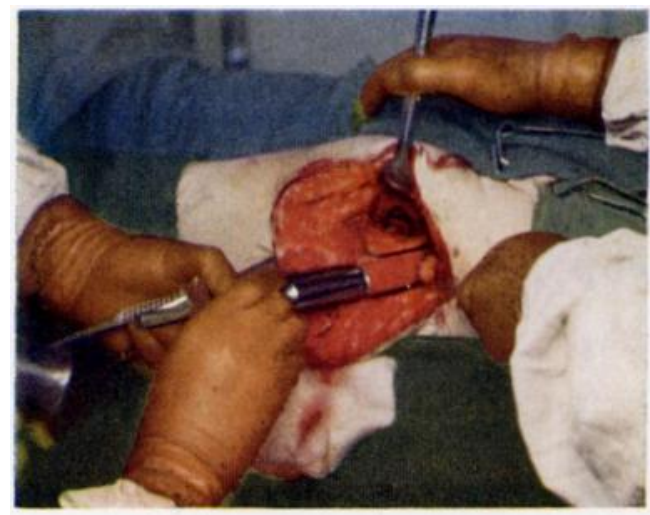

FIG. 17

The drill is passed through the femur into the ischium (Fig. 12). When the position has been verified radiographically the osteotomy is started (Fig. 13). If the posterior limit of the chisel is in front of the posterior margin of the greater trochanter, and the chisel is kept in the horizontal plane, the sciatic nerve cannot be struck. Fig. 14 shows the chisels being separated by means of a special screw, so that the cleft in the ischium is made wide enough to receive the graft. The male chisel is then tapped out (Fig. 15). The greater trochanter is hooked up with a retractor and the graft is introduced along the female chisel (Fig. 16).

The graft is punched home (Fig. 17). 
certain to engage in bone in the ischium, though not necessarily in the tuber ischii. One may aim at a large target with a small arrow, but here one is aiming at a small target with a large bludgeon, and if any part of the bludgeon hits the target, success is probably assured. At first it is difficult to cut a graft which includes the postero-lateral and postero-medial borders of the tibia, but with practice this becomes simple. An additional advantage is that, since the width of the tibia has been decreased, the periosteum may be sutured without tension and the haematoma is enclosed, thus encouraging regeneration of the bone. After the graft has been taken it is shaped with the electric saw so that one end resembles a chisel.

3) A curved incision with the convexity passing upwards is made, starting one inch above the greater trochanter and finishing four inches distal to it. A straight incision is made down to bone through the vastus lateralis throughout the limits of the incision, and the

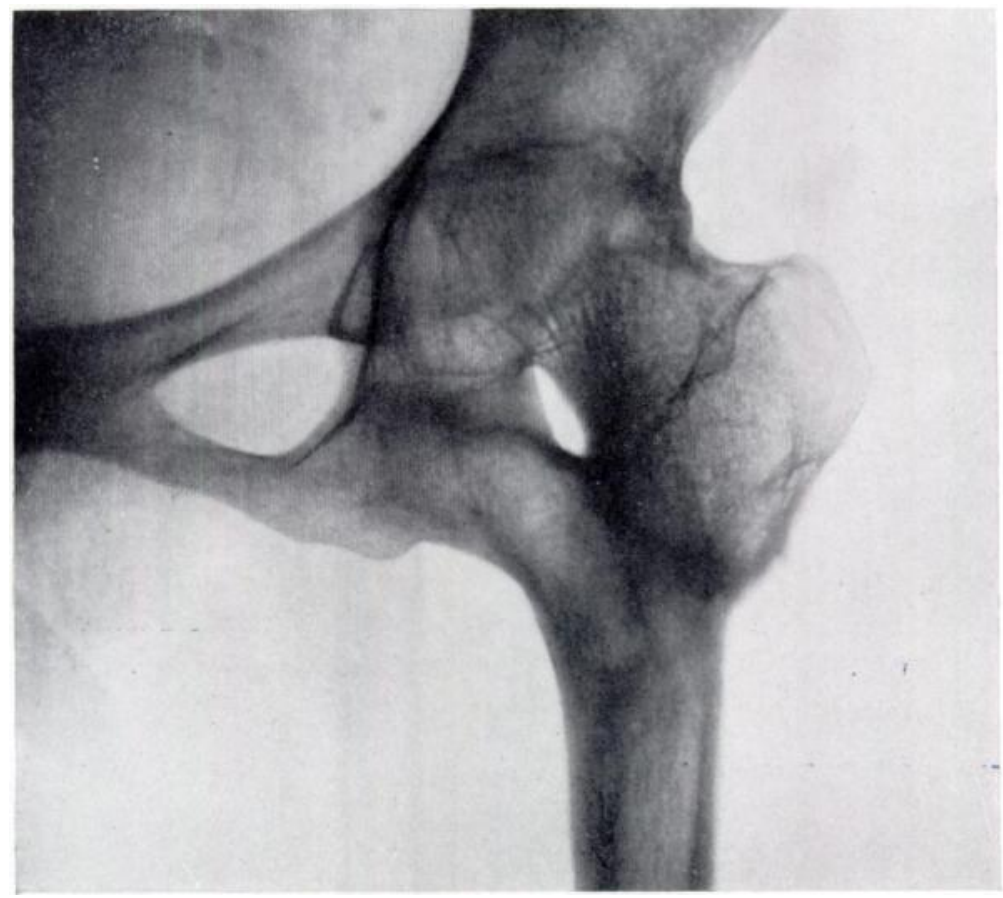

FIG. 18

Tuberculous hip, operated on at the age of fifteen years after twenty months of disease. Radiograph eight years after operation. Note the apparent reformation of a medullary canal in the graft.

shaft of the femur is cleared. A site for osteotomy is chosen, bearing in mind that the lower limit of the greater trochanter is a point which is easy to verify, and that the Michel clips are an additional guide.

4) A small hand-drill is introduced through the femur at an angle of 45 degrees in the coronal plane, aiming at one of the Michel clips. After the inner wall of the femur has been pierced there is lack of resistance until the ischium is struck. The position of the drill is verified by an X-ray photograph.

5) A subtrochanteric osteotomy is performed. Special chisels are used with a screw to separate them, one chisel with a slot and shoulders to receive the other. After the osteotomy has been performed by one chisel (the male) it is tapped gently inwards until it engages in the ischium. An X-ray photograph is then taken, and the female chisel is introduced below the first. 


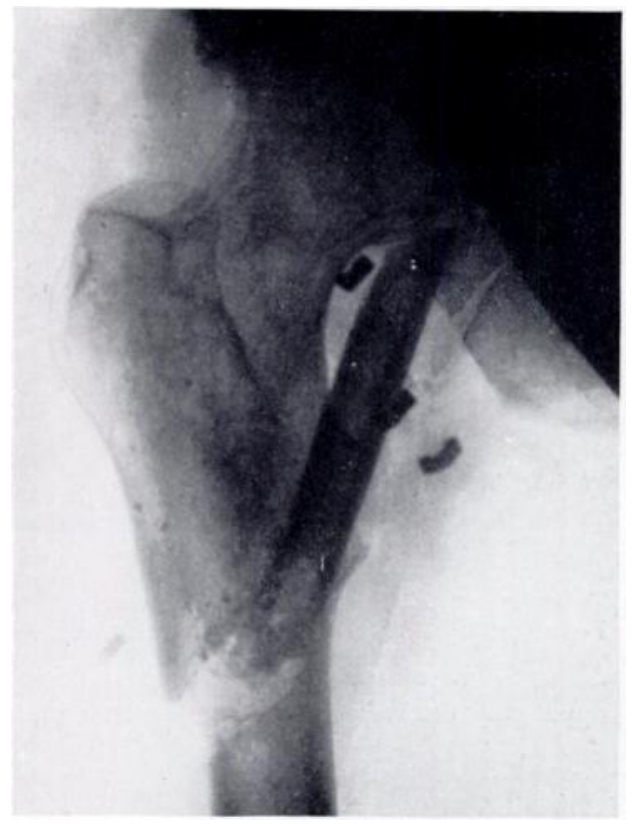

FIG. 19

Case illustrating the difficulty of placing the graft in the ischial bone cleft, unless special chisels are used.

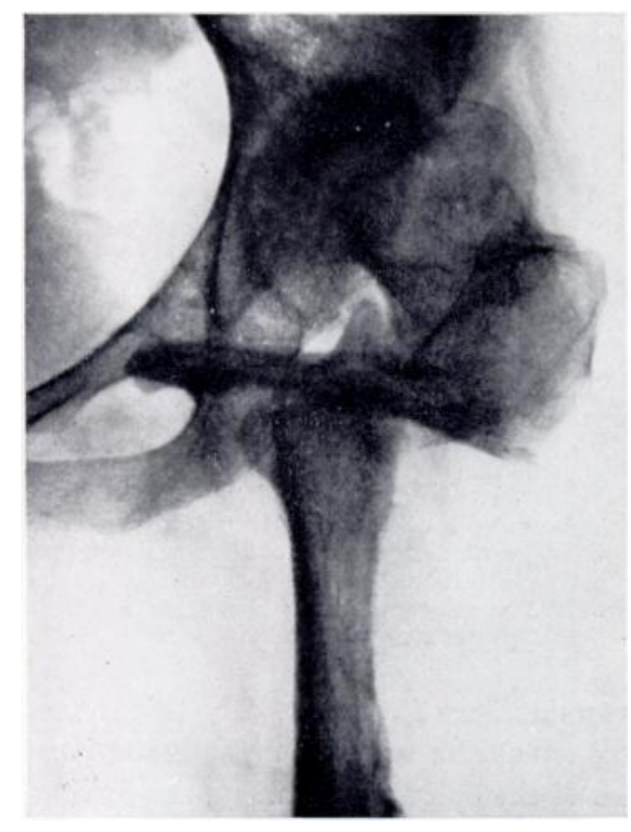

FIG. 21

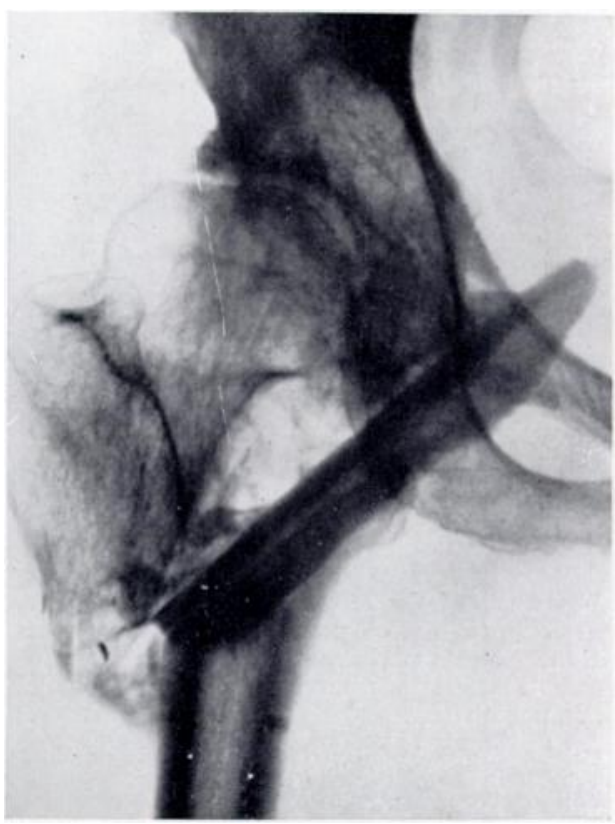

FIG. 20

Man aged fifty-four years, with osteoarthritis of the hip joint. Graft well placed. Radiograph six months after operation.

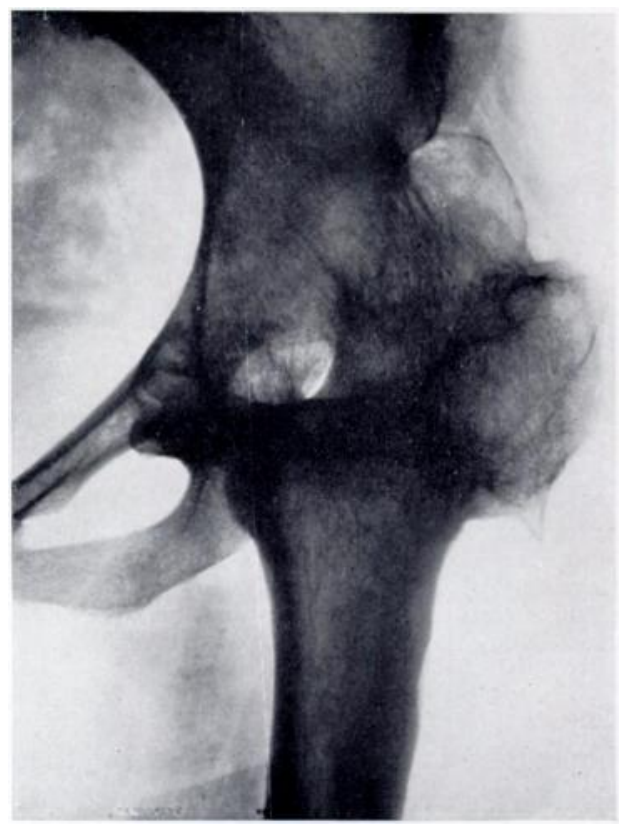

FIG. 22

Congenital subluxation of the hip joint with secondary arthritis, in a patient aged twenty-eight years. Fig. 21 is the radiograph taken six months after ischio-femoral arthrodesis, using a graft from the femur. Fig. 22 shows the same hip joint eight years later. Note, not only that the ischio-femoral fusion is sound, but that the hip joint is consolidated; no intra-articular operation was performed.

Vol. $30 \mathrm{~B}$, No. 4, NOVEmber 1948 


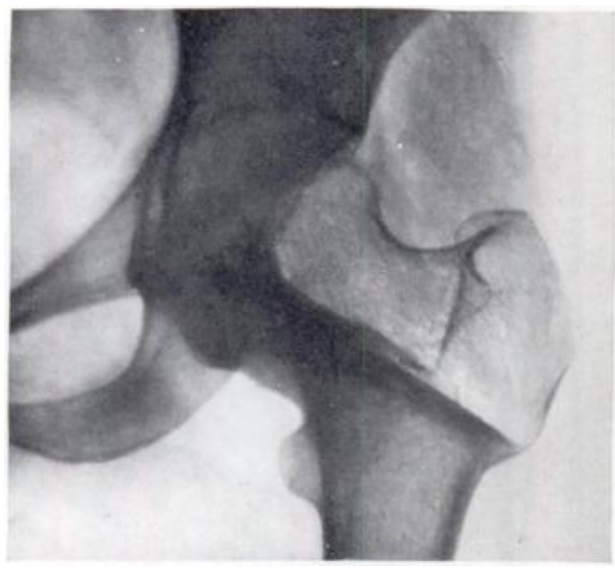

FIG. 23

Tuberculssis of the left hip joint in a patient aged twenty-three years. Ischio-femoral arthrodesis was performed in 1942 . Note the porosis in the upper part of the femoral head, the femoral neck, and the greater trochanter. which are not now weight-bearing.

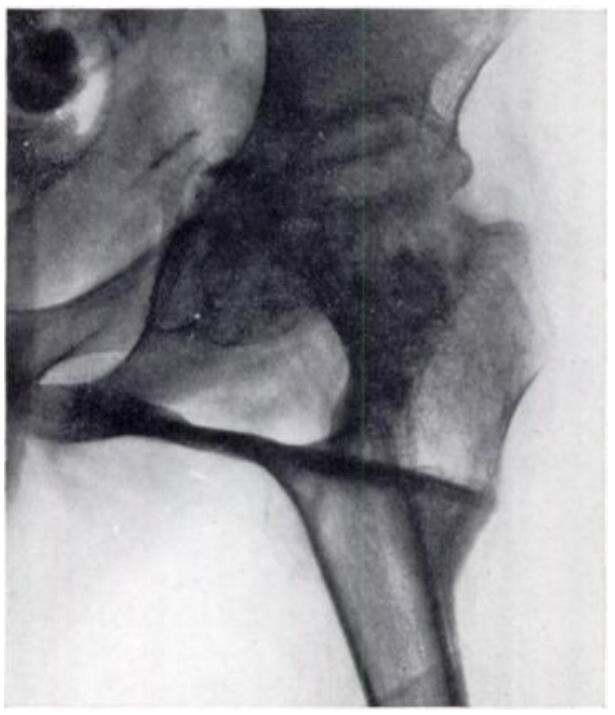

Fig. 25

Boy aged seventeen years with very active tuberculous disease of the hip. The graft was deliberately placed far from the hip joint into the ischial ramus. Radiograph one year after operation shows that the disease is healing.

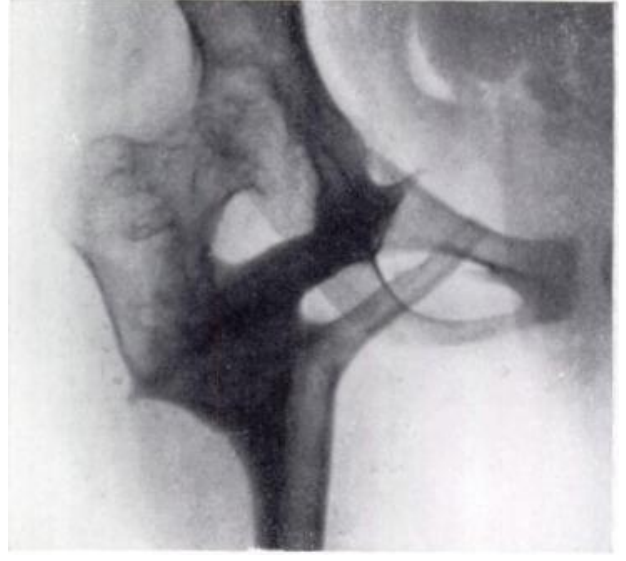

Fig. 24

Tuberculous hip, patient aged fifteen vears. Four operations were needed before ankylosis was sound. The lower graft failed becaluse it passed through the obturator foramen. The upper graft has fused. Remnants if other grafts can be seen.

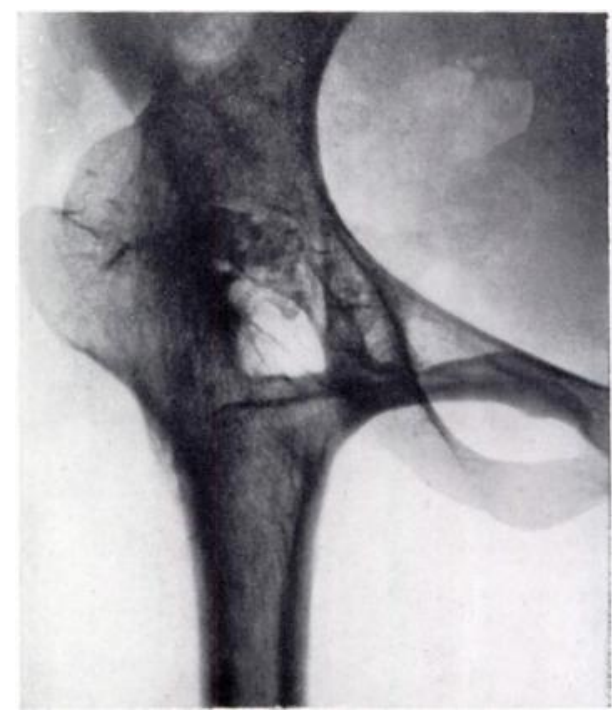

Fis. 26

Tuberculosis of the right hip joint, fused at the age of sixteen years after ten years of active disease. In this case the graft has united to the ascending pubic ramus. Radiograph nine years after operation.

6) The chisels are separated gradually by the introduction of a screw. By this means a $V$-shaped slot is made in the ischium; the entrance should be wider than the graft it is to receive. This overcomes one of the chief difficulties of the operation, namely, the finding of the cleft in the ischium by the graft.

7) The male chisel is then withdrawn. The greater trochanter is hooked upwards with a retractor, and the graft is tapped in along the female chisel. As it is tapped in, the female chisel is withdrawn. After the graft is felt to engage in the cleft in the ischium it is punched firmly home. If any difficulty is met in finding the cleft, it may be felt by the finger. The 
middle finger is inserted in front of the greater trochanter and below the neck of the femur. In our last dozen cases we have had no difficulty in feeling the cleft.

8) The distal fragment of the femur is displaced inwards with a punch until it makes contact with the ischium, thereby supporting the middle part of the graft.

9) A double plaster spica is applied and maintained for at least four months, or until fusion occurs.

\section{COMPLIGATIONS}

It has been stressed that this operation is difficult because it is blind. For this reason there must be a clear visual conception of the anatomy. The dangers are: a) striking the sciatic nerve; $b$ ) haemorrhage.

Striking the sciatic nerve-This should not occur. If the posterior edge of the chisel is in front of the posterior margin of the greater trochanter, and the chisel is maintained horizontally, the sciatic nerve cannot be struck. The nerve can be hit only if the chisel is directed posteriorly. In the course of many operations on the cadaver I have found that unless the chisel is directed at an angle of $\mathbf{4 5}$ degrees to 60 degrees backwards it is impossible to hit the nerve. There may perhaps be some danger when there is adduction deformity of the hip. In the flexed hip more care has to be exercised because the sciatic nerve may be on the stretch. It should be understood clearly that the area of bone at which one is aiming is not the tuber ischii but the bifurcation of the pelvic rami below the acetabulum, consisting of the anterior ramus of the pubis and the posterior ramus of the ischium. At this level the sciatic nerve is far behind, and it cannot be struck by a chisel which is placed horizontally.

Haemorrhage-Some oozing always takes place, and sometimes it may appear alarming. If the anterior pelvic brim is traversed, the obturator artery may be divided. In addition. one may divide branches of the lateral femoral circumflex artery taking part in the digital anastomosis, and there may be muscular oozing from dividing the iliopsoas and small muscle like the piriformis and obturators. None of this haemorrhage is serious, with the possible exception of that from the obturator artery in a debilitated patient. There is no doubt that oozing does take place and that it goes on after the operation, so that it is wise to have blood transfusions readily available. I have had no fatalities from haemorrhage, and shock is the exception rather than the rule. McMurray's statement that there is more shock after this operation than after any other method of arthrodesis is, in my experience, entirely without foundation. I would state dogmatically that if the operation is performed with correct technique there is much less shock than with any other method.

\section{REASONS FOR FAILURE OF FUSION}

The possible causes of failure are: 1) passing the chisel or graft through the obturator foramen, thus securing inadequate ischial contact; 2) non-union between the osteotomised femoral fragments, or between the graft and the femoral fragment at the outer end; 3) extension of disease into the area of the graft.

Passing the chisel or graft through the obturator foramen-Striking bone is, of course, of paramount importance, and it is wise to take the precaution of using a drill or guide as suggested by Freiberg (1946). I have adopted this measure during the past two years. In earlier observations I stated that the obliquity of the obturator foramen was such as to prohibit the passage of a graft through it, but this statement has had to be modified in the light of further experience. A graft directed transversely and horizontally may pass through the obturator foramen, especially in children where the tibia is not wide. Once again, a wide tibial graft is essential for this operation. If disease permits, the graft may be directed more vertically, when it is certain that bone will be struck. Extension of tuberculous disease may of course determine the position of the graft, but whenever possible the graft should approximate towards the vertical position.

vol. $30 \mathrm{~B}$, No. 4, NOVEMBER 1948 
Non-union between the osteotomised femoral fragments, or between the graft and the femoral fragment at the outer end-In three patients fibrous union occurred between the greater trochanter and the distal fragment of the femur. In two patients a second operation was performed, and union occurred after freshening these surfaces. This, of course, is a minor operation as compared with the major problem of securing fusion of the diseased hip. It is now my custom to fragment the outer surface of the greater trochanter and to place the bone chips in the site of osteotomy.

Extension of disease into the area of the graft-Extension of disease may be beyond the control of the surgeon. It seldom happens, but if it does the indication is for more prolonged immobilisation. Once there is no doubt that the graft has become diseased, the operation should be repeated. It is an important point that the second operation is less difficult than the first because the upper end, and the direction, of the first graft can be identified easily.

It must be emphasised that one of the essential features of the operation is that it is closed, and that its success may depend upon this. Wider exposures, which mobilise both femoral fragments in the attempt to see what one is doing, lose the advantage of fixation of the graft between the fragments and may cause non-union.

\section{Results of Ischio-femoral Arthrodesis}

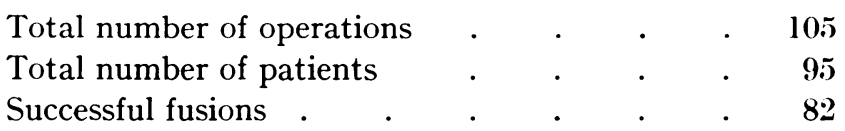

Tuberculosis of the hip -38 patients; 48 operations; 32 fusions.

Two patients required 4 operations; one, 3 operations; and two, 2 operations.

Osteoarthritis of the hip- $\mathbf{5 2}$ patients; $\mathbf{4 5}$ fusions.

In seven cases the arthritis was secondary to congenital dislocation of the hip; one patient aged fifty-eight years died eight days after operation from pulmonary embolism confirmed by post-mortem examination.

Infective arthritis of the hip -5 patients; 5 fusions.

\section{SUMMARY}

It will be seen that the proportion of successful fusions in this series of ninety-five patients treated by ischio-femoral arthrodesis of the hip was over 80 per cent. Similar percentages of successful fusion have been reported by Knight (1945), Freiberg (1946), Langston (1947), and Nisbet, who was resident surgical officer at the Robert Jones and Agnes Hunt Orthopaedic Hospital, and informed me in a personal communication that he had carried out twenty-six operations with an approximate fusion rate of 80 per cent. He stated: "It is the only operation which gives a reasonable chance of a successful arthrodesis in children. Up till now at Oswestry the chances of a fusion by the other methods in children have proved so disappointing that the operation had been abandoned. Dame Agnes Hunt, with her vast experience of the condition, was always very annoyed when she found a surgeon trying to fuse a child's hip. All this has been changed."

\section{REFERENCES}

Brittain, H. A. (1941): Ischio-femoral Arthrodesis. British Journal of Surgery, 29, 93.

Brittain, H. A. (1942): Architectural Principles in Arthrodesis. Edinburgh: E \& S. Livingstone, Ltd.

Freiberg, J. A. (1946): Experiences with the Brittain Ischio-femoral Arthrodesis. Journal of Bone and Joint Surgery, 28, 501.

KNight, R. A., and Bluhm, M. M. (1945): Brittain Ischio-femoral Arthrodesis. Journal of Bone and Joint Surgery, 27, 578.

Langston, H. H. (1947): The Brittain Method of Arthrodesis of the Hip. Proceedings of the Royal Society of Medicine (Section of Orthopaedics), 40, 895. 